\title{
$>$ Cópia e Simulacro: potencialidades da representação da doméstica em Carolina Maria de Jesus
}

$>$ Copy and simulacrum: potentials of domestic representation

in Carolina Maria de Jesus

\section{por Milena Paixão Silva}

Doutoranda em Literatura e Cultura na linha de pesquisa Documentos da Memória Cultural do Programa de Pós-graduação Literatura e Cultura da Universidade Federal da Bahia (UFBA).E-mail: millapaixao7@yahoo.com.br. ORCID: 0000-0002-8448-3200.

\section{Resumo}

Este trabalho busca pensar se a produção literária, sobretudo as bem próximas dos caracteres autobiográficos, nos permitem dialogar com o conceito de cópia e simulacro, primeiramente apresentado por Platão em A República e depois revisitado por Gilles Deleuze em Platão e o Simulacro. Não por acaso, escritos de Carolina Maria de Jesus presentes na obra Diário de Bitita, assim como o poema-narrativo A Empregada são escolhidos para essa tarefa. $O$ recorte descreve algumas das vivências de Carolina enquanto doméstica, o que oportuniza a discussão sobre autoconhecimento e representação.

Palavras-chave: Carolina Maria de Jesus. Autoconhecimento. Representação.

\begin{abstract}
This work seeks to consider whether literary production, especially those very close to autobiographical character, allow us to dialogue with the concept of copy and simulacrum, first presented by Platão in A República and later revisited by Gilles Deleuze in Platão e o Simulacro. Not by chance, writings by Carolina Maria de Jesus present in Diário de Bitita, as well as narrative poem A Empregada are chosen for this task. The clip describes some of Carolina's experiences as a domestic, which provides the opportunity for discussion about self-knowledge and representation.
\end{abstract}

Keywords: Carolina Maria de Jesus. Self-knowledge. Representation. 


\section{Conhece-te a ti mesmo: considerações iniciais}

O famoso aforismo do mundo grego Conhece-te a ti mesmo, inscrito no Oráculo de Delfos - Templo de Apolo, deus da luz, do sol, da verdade e da profecia - parece apontar para algumas questões bem significativas para os seres humanos. A primeira diz respeito à busca pelo autoconhecimento e compreensão da realidade como uma longínqua necessidade humana. A segunda, moldada na forma imperativa-reflexiva do verbo conhecer indica que, seria o Outro, enquanto divindade ou não, aquele que nos despertaria para essa necessidade. Outro possível entendimento é que a máxima desenha o alcance do autoconhecimento mediante constante exercício, já que alcançá-lo não ocorreria em experiências isoladas, trata-se de um processo.

Enquanto processo, que certamente percorre toda a existência do sujeito, não seria difícil concordar que são variados os eventos, meios e instrumentos que oportunizam o exercício do autoconhecer-se. Essas oportunidades se efetivam desde a simples análise da matéria corpórea que realizamos diariamente diante do espelho até as mais profundas reflexões possibilitadas pela vivência de distintos eventos em nossas vidas. Nesse sentido, acredita-se que a literatura se constitua como uma relevante ferramenta para o exercício do autoconhecimento.

De posse do texto literário, somos convidados a nos libertarmos das amarras do cotidiano, refletindo sobre o real e vivendo a experiência de nos vermos pelos olhos do outro, contexto em que se manifesta o que compreendemos como representação. O grande acervo que a humanidade vem produzindo e acumulando ao longo de sua história pode dar a dimensão do 
quanto temos nos (re)pensado por meio da leitura literária, melhor, por meio da representação da realidade forjada pela literatura.

A princípio, viver a experiência da representação da realidade e da busca pelo autoconhecimento caberia, de forma mais geral, aos leitores do texto literário. Contudo, este trabalho propõe-se a pensar, mesmo que brevemente, outros movimentos. A proposta é refletir como o produtor do texto literário, por exemplo, estabelece possíveis relações de autoconhecimento representativo por meio da sua própria escrita.

Para observar esse movimento, parte-se das noções platônicas sobre as ideias de cópia e simulacro, revistas pelo pensamento de Gilles Deleuze ${ }^{1}$ e atravessadas pelo texto literário de Carolina Maria de Jesus. Destaca-se, para tanto, um recorte da obra da escritora que descreve eventos pessoais de suas vivências enquanto doméstica, registrados no seu livro de memórias Diário de Bitita $^{2}$, e o texto poético-narrativo A Empregada ${ }^{3}$, um possível exemplo de autoconhecimento e forjamento da realidade. Antes de iniciar a análise, contudo, parece pertinente apresentar Carolina, mesmo que brevemente, para o leitor que não a conheça.

\footnotetext{
${ }^{1}$ Gilles Deleuze, "Platão e o simulacro", 2015.

${ }^{2}$ Carolina Maria de Jesus, Diário de Bitita, 2014.

${ }^{3}$ Idem, "A Empregada", 2018.
} 


\section{Conheces Carolina? Breves notas biogratextuais ${ }^{4}$}

A história de Carolina Maria de Jesus e sua produção são altamente imbricadas, o que motivou a escolha da escritora e de alguns dos seus escritos para a discussão aqui proposta. Sua trajetória não foi o que se considera como convencional. Enquanto mulher negra, com poucos anos de estudos formais e, por certo tempo, moradora de favela, esperava-se que Carolina de Jesus fosse comedida, submissa e ignorante, mas ela não coube nessas caixas. Seu corpo decolonial constantemente performatizava a contrapelo do que lhe era esperado. Assim, ela foi exuberante, independente e sábia e transportou esses predicados para sua vasta produção.

Nascida no interior de Minas Gerais, apenas 26 anos após a assinatura da Lei Áurea, Carolina Maria de Jesus testemunhou, quando criança, as primeiras décadas da dita liberdade dos escravizados, contada pela História Oficial. Seus relatos em Diário de Bitita, publicado primeiramente na França e depois no Brasil quase uma década após sua morte, registram a dificuldade que a menina teve em compreender um dito regime libertário, que passou a vigorar a partir de 1888, e que manteve os corpos negros em uma estrutura de servidão. ${ }^{5}$

Seus escritos revelam inúmeras passagens que escancaram as hostilidades contra negros e negras, as constantes e contraditórias detenções e o trabalho servil aparentemente contratado, mas caracterizado por um perverso ciclo vicioso de uma remuneração sempre parca ou nula. Nesse período histórico

\footnotetext{
${ }^{4} \mathrm{O}$ neologismo busca marcar o imbricamento entre os dados biográficos de Carolina Maria de Jesus e sua produção.

${ }^{5}$ Carolina Maria de Jesus, Op. Cit., 2014.
} 
brasileiro, as negras libertas prosseguiam trabalhando como serventes (diferentemente de hoje?) e as meninas precisavam aprender as tarefas do servir e do cuidar o mais precocemente possível.

Carolina não pôde se esquivar dessa conjuntura, sempre acompanhando e ajudando sua mãe que realizava serviços de lavadeira e cozinheira nas fazendas da região ou nas grandes casas da cidade. As diferentes fases da vida da escritora foram permeadas pelo aprendizado e realização de ofícios do servir tanto para o seu sustento como o da sua família. Dentre outras funções que exercera ao longo da vida, Carolina fora faxineira, cozinheira, arrumadeira, lavadeira, passadeira e babá.

Diante desse contexto, o diferencial de Carolina Maria de Jesus parece apoiar-se na compreensão, ainda em tenra idade, da importância do domínio do código escrito. Foram apenas dois anos de estudos formais, realizados no Instituto Allan Kardec, atual Colégio Eurípedes Barsanulfo, localizado em Sacramento-MG, e incentivados por D. Mariquinhas Leite, uma patroa de sua mãe.

O acesso à escolarização pela população negra era um abismo. Segundo Santos, isso se deve ao fato de que, iniciada a República, era preciso decidir o rumo a ser tomado pelo Brasil e a desmontagem do sistema escravista sofria simultâneos avanços e recuos devido tanto ao temor nutrido pelos ex-senhores de escravizados quanto ao afrouxamento do sistema vigente até inícios de $1888 .^{6}$ Assumia-se que mudanças eram necessárias, mas elas deveriam ser implantadas

\footnotetext{
${ }^{6}$ Rosimeire Santos, A escolarização da população negra entre o final do séc. XIX e o início do séc. XX, $\mathrm{s} / \mathrm{d}, \mathrm{s} / \mathrm{p}$.
} 
paulatinamente porque, se repentinas, poderiam prejudicar o bom andamento da economia, um contexto também não tão diferente do atual.

O sistema educacional, decerto, fazia parte das mudanças e, ao analisar alguns dispositivos legais que versavam sobre a educação brasileira no início da República, Santos observa como as prescrições desses dispositivos não tencionaram possibilitar o efetivo acesso da população brasileira, recém-liberta, à escolarização. ${ }^{7}$ Talvez isso explique porque em Sacramento, que contabilizava mais de quinze mil habitantes na época de nascimento de Carolina Maria de Jesus, só houvesse um grupo escolar público.

Contudo, estudar era um desejo da menina Carolina e um privilégio de poucos, sobretudo, quando negros e negras. É possível imaginar quais e quantas foram as violentas experiências vividas por crianças de famílias negras, como a de Carolina, que tentaram acessar a escola nas primeiras décadas de República. Nessas famílias, os adultos traziam suas memórias e corpos marcados pelo doloroso processo de escravização; para eles, incentivar o acesso e permanência na escola não era uma tarefa psicologicamente fácil. Foram, certamente, incontáveis os desafios vividos pela menina Carolina, especialmente porque sua família, como tantas outras famílias negras, residia longe de um grande centro urbano.

Enfrentar, resistentemente, cada uma das truculentas experiências vividas durante a aquisição e desenvolvimento da leitura e da escrita, todavia, desaguou no acontecimento que pautaria, a partir de então, a sua vida. Dessa forma, Carolina renasce e transporta-se para um espaço onde essas práticas são

\footnotetext{
${ }^{7}$ Ibidem, s/p.
} 
valoradas. E tais ferramentas de força e resistência passariam a acompanhá-la ao longo de sua trajetória.

Os parcos anos na escola foram decisivos para o autoconhecimento de Carolina de Jesus, seu entendimento do mundo e de sua arte. Carolina dedicou boa parte do seu tempo, a partir da aquisição do código escrito, à leitura e à escrita. Na sua vasta produção, a escritora parece sempre refletir sobre a sua condição e dos seus pares. Em Diário de Bitita, por exemplo, ela chega a registrar que a condição de servente é humilhante, devido às provações e privações vividas por aqueles que a realizavam. ${ }^{8}$

Em um dos episódios descreve que fora presa - acusada de roubo - e fala da truculência que quase fora exercida sobre seu corpo negro, salvo por um telefonema que explicava o mal entendido. Prossegue ainda concluindo que todos os pretos deveriam esperar por isso. No capítulo Ser Cozinheira, um dos suportes para as análises aqui propostas, ela relata “[...] eu já sabia que posteriormente aos interrogatórios vinha uma observação. Eu tinha a impressão de que estava num duelo e deveria ficar em guarda. Prevenida para receber o golpe"

Apesar dos termos interrogatório, duelo e golpe, a passagem não alude à prisão mencionada anteriormente. Nela é registrado o serviço realizado como cozinheira na Santa Casa de Misericórdia. O duelo refere-se à convivência com suas patroas, as religiosas responsáveis pela instituição. O que chama atenção é que Carolina de Jesus descreve esse trabalho como o melhor daquela fase de sua

\footnotetext{
${ }^{8}$ Carolina Maria de Jesus, Op. Cit., 2014, p. 148.

${ }^{9}$ Ibidem, p. 201.
} 
vida. A maior remuneração que já recebera, camisola e cama limpinhas para dormir e até luz elétrica. Contudo, consciente da condição a ela impelida, era preciso estar constantemente em alerta para receber os duros golpes que certamente seriam lançados sobre seu corpo negro.

Não obstante, em outro trecho do capítulo é registrado:

Trabalhei 3 meses para a senhora Salima, ia ganhar 40 mil-réis por mês. Quando vencia o mês, eu tinha vergonha de cobrá-la. Quando completaram-se 90 dias, decidi cobrá-la. Ela deu-me apenas 10 mil-réis. Eu disse:

- Só?

- Respondeu-me:

- Se não está contente pode deixar minha casa.

Chorei pensando na quantidade de roupa que eu lavava e passava. Cuidar do quintal, olhar a casa quando ela estava ausente. Não roubava. Cuidava de tudo como se fosse meu. Decidi procurar outro emprego. Ou deixar o anterior.

Pretendia encontrar um trabalho com melhor remuneração. Eu tinha que aprender a reagir, a exigir respeito nos contratos de trabalho. Mas não tinha casa e já estava cansando da vida de andarilha.

A patroa era estrangeira e eu nacional. Eu não podia competir com ela. Ela era rica e eu pobre. Ela podia mandar me prender. Continuei trabalhando.

A patroa sorria dizendo que havia encontrado uma idiota que trabalhava quase de graça. Depois do jantar, eu saía andando pela cidade, procurando emprego. Eu estava sã. Não havia obstáculo para impedir-me. ${ }^{10}$

A passagem relata mais um episódio de contrato de serviço que não fora cumprido. Segundo dados biográficos, a senhora Salima fora uma das últimas patroas para quem Carolina de Jesus trabalhou em sua região antes da mudança

${ }^{10}$ Ibidem, p. 204-205. 
para São Paulo, que aconteceria um pouco depois desse evento. A senhora Salima passava grandes temporadas fora da cidade e deixava o imóvel sobre os cuidados de Carolina, um gesto que supostamente demonstrava confiança. Em contrapartida, Carolina dedicara-se a ele como possivelmente se dedicaria à sua própria casa. Mas o desfecho do episódio mostra como as relações entre patrões e serventes negros estavam longe do respeito aos acordos firmados.

As passagens de casa em casa, de fazenda em fazenda, de cidade em cidade rendiam experiências malsucedidas, talvez por isso fossem tão frequentes as mudanças. A própria mãe de Carolina não conseguia compreender como sua filha, que dominava os códigos de contagem e escrita, ao contrário, inclusive, de muitas de suas patroas, era constantemente espoliada. No caso da senhora Salima, a manifestação explícita de má fé diante dos serviços prestados pelo corpo negro que lhe servia, gera ainda mais indignação.

Durante o período que Carolina de Jesus passara na casa de tal senhora, houve certa cicatrização das feridas em suas pernas, possível problema de circulação que acometeu a escritora por muitos anos. Mas a falta de pagamento do valor acordado na contratação e, sobretudo, a explícita dissimulação da patroa fizeram com que Carolina buscasse mais uma vez outro trabalho, possivelmente também relacionado ao servir.

Os relatos em Diário de Bitita localizam-se no tempo e espaço de uma infância e adolescência pobre, onde recorrer ao serviço doméstico era a opção de sustento. Anos depois, Carolina Maria de Jesus escreve o poema-narrativo A Empregada, publicado graças ao esforço em acessar uma parte da vastidão de seus manuscritos. O texto autobiográfico, com nítido espelhamento em vivências da 
escritora, descreve uma condição servil individual dos corpos femininos negros, mas pode também ser compreendido dentro de uma discursividade coletiva.

Uma jovem deixou o interior e veio empregar-se em São Paulo para ganhar mais. Não apreciou o São Paulo com seu bulício diário e o seu clima enigmático. Enfim, ela estava descontente e regressou ao interior. As amigas foram cumprimentá-la e foram saber que tal é São Paulo. Ela respondeu-lhes assim:

Quando eu era empregada

Sofri tanta humilhação

Às vezes eu tinha vontade

De dar uma surra no meu patrão

Era um patrão malcriado

Não deixava eu parar um segundo

E o diabo ainda falava

De mim para todo mundo.

Obrigava eu levantar

A uma da madrugada.

E ainda andava dizendo

“Essa malandra não faz nada"

Se a gente dá um passo,

O diabo está sempre atrás

Vive sempre pondo defeito

Em todo serviço que a gente faz

Não gostei de trabalhar

Foi para as donas de pensão

Que quer tudo muito limpo 
Mas não quer comprar sabão

Se a gente dá um passo

A diaba está sempre junto

Vive sempre observando,

Se a empregada come muito

Vive sempre pondo defeito

Em todo serviço que a gente faz ${ }^{11}$

A escrita poética do texto expressa as experiências de Carolina Maria de Jesus, nas provações e privações de sua vida servil. Aproxima-se, decerto, do que fora vivido na juventude pela escritora, como uma plasmagem entre a arte e a realidade. Essa plasmagem é permitida pela representação, que enquanto conceito filosófico significa estar por. Assim, na representação o representante está pelo representado, num exercício que tenta buscar compreender a capacidade de nos percebermos a nós mesmos e também ao mundo. No texto, é construída uma rede de imagens e ideias que, individualmente, alcança o coletivo.

Como observado, os textos selecionados marcam o imbricamento entre as vivências pessoais da escritora, no que tange a sua impelida e árdua condição de servente e a sua produção artística e literária. Esse imbricamento é a base para a discussão aqui pretendida. Nesse sentido, a investigação proposta visa

\footnotetext{
${ }^{11}$ Carolina Maria de Jesus, Op. Cit., 2018, p. 84-85.
} 
compreender certos níveis de representação que podem ser estabelecidos entre as experiências da escritora e seus escritos.

Assim, para tal discussão, um esforço é feito na busca de se construir um diálogo entre os níveis de representação apresentados por Platão em A República e a análise deleuziana sobre essa dialética platônica. Distinguir as boas das más cópias classificaria o tangível na representação da realidade, segundo Platão. Contudo, questiona-se se a produção caroliniana poderia ser concebida, em certa perspectiva, tanto como boa quanto como má cópia. E sendo uma má cópia - o simulacro - ela seria desprovida de potência? Tais questionamentos norteiam a análise a seguir.

\section{0 texto caroliniano: potencialidades enquanto cópia e simulacro}

As discussões e informações apresentadas acima tiveram como objetivo iniciar um caminho que busca entender se a produção literária, sobretudo as bem próximas dos caracteres autobiográficos, nos permitem dialogar com o conceito de cópia e simulacro, primeiramente apresentado por Platão e, séculos depois, revisto por Gilles Deleuze. Não por acaso, os escritos de Carolina Maria de Jesus que foram citados são escolhidos para essa tarefa, acredita-se que eles possibilitam o estabelecimento de tal diálogo.

Como ponto de partida, entende-se que seja pertinente situar alguns usos, tanto do termo cópia, como de simulacro. Socialmente, a ideia de cópia parece assumir, em geral, uma contextualização negativa. Sua realização, sem conhecimento e autorização prévia é, inclusive, enquadrada como crime em 
dispositivos legais. Pensemos, por exemplo, no campo acadêmico: copiar parcial ou integralmente um escrito, sem atribuir o devido crédito ao autor é considerado plágio. No campo artístico, da mesma forma, a cópia é compreendida como ato criminoso, assim como o é na indústria.

Quanto ao conceito de simulacro, o contexto de negatividade, de forma extensiva, parece ser ainda mais acentuado. Também passível de sanções legais, por relacionar-se a ações criminosas, o termo liga-se, frequentemente, à ideia de imitação defeituosa ou malfeita, onde a aparência é enganadora e a atmosfera é envolta por fingimento. Tal entendimento talvez seja atenuado em se tratando de campo artístico e/ou literário, ironicamente ao concebido por Platão no século IV a.C.

Nessa perspectiva, é possível compreender que os usos sociais tanto do termo cópia como do termo simulacro, via de regra, são contraproducentes já que ambas ações não passariam de mera imitação, sem o emprego de um esforço criativo ou crítico. A diferença é estabelecida, então, na ideia de que a cópia seria uma imitação, ao menos, bem feita do original e o simulacro uma imitação malsucedida do mesmo. Mas o que tem sido marcado de tais termos desde Platão?

Para pensarmos uma possível resposta, voltemos ao aforismo Conhece-te a ti mesmo que contorna essa análise. Buscar, dentre tantos conhecimentos, aqueles que nos fazem olhar para dentro de nós mesmos e nos ajudam a nos autoconhecer para, em seguida, distinguir, conscientemente, entre o real e o representado, por meio de tal conhecimento e ainda transpor esse exercício para o mundo exterior é, sem dúvida, uma atitude de grande sabedoria. 
Tal aforismo não é creditado a Platão, mas certamente ele foi o primeiro (ou um dos primeiros) a pensar sobre o nexo entre a realidade e a representação. Para o filósofo grego, a arte está para o real como o real está para as ideias. Assim, a realidade é representada e a arte acaba sendo a imitação dessa realidade. A proposta platônica é, grosso modo, classificar os níveis miméticos de distanciamento da realidade. Nessa conjuntura, quanto maior a distância do que é considerado como original, maior será a precariedade da imitação.

Enquanto mímesis da realidade, a arte assumiria um acentuado distanciamento do nível original. Em A República - diálogo socrático escrito por Platão, em que o filósofo busca pensar a fórmula ideal para os mecanismos de convivência social - os poetas, assim como os sofistas, não estariam em busca da verdade (condição fundamental para uma vivência plena em sociedade). ${ }^{12}$ Para ele, os poetas seriam meros produtores de imagens, habilidade desenvolvida pela arte da cópia e, sobretudo, do simulacro.

A crítica feita à poesia na obra platônica, relaciona-se com a ideia de que tal arte literária não seria um bom instrumento para a formação dos jovens dentro de uma sociedade perfeita, uma vez que a poesia exalta os deuses que são, na visão do filósofo, tão imperfeitos quanto os homens. Outro problema da poesia é que ela abordaria temas como a morte e a política de maneira inadequada. A melhor ferramenta para essa tarefa, segundo Platão, seria a educação filosófica, obviamente.

Desse modo, a dialética platônica não estaria baseada no princípio da contradição, mas sim da competitividade. A fim de distinguir o falso do

${ }^{12}$ Platão, A República, 2014, p. 373-416. 
verdadeiro, essa dialética busca uma categorização que diferencie o que é original do que seria a imitação, até porque o objetivo é mostrar uma dita verdade, contida na origem, e não um forjamento dela, expressa nas imitações. Assim, os três níveis de categorização, pensados pelo filósofo, classificam mais precariamente os modelos quanto maior se caracteriza o afastamento do considerado nível original.

Nessa perspectiva, o original é, como se sabe, o primeiro nível, atribuído ao mundo das ideias. Já o segundo é o nível inteligível, entendido como essência. E o terceiro é o nível fenomênico que representa os sentidos, objetos e aparências. Diante dessa categorização, a dialética platônica defende que o tangível deve ser concebido como cópia dos arquétipos ideais e, enquanto cópia, o tangível é imperfeito porque se afasta da ideia primeira que a originou. E quanto ao simulacro?

A partir de tal contexto, o pensamento platônico compreende que há cópias que advém, não da ideia original, mas da realização de outras cópias. Às cópias concebidas por meio de outras cópias, Platão conceitua como simulacros. Dessa forma, a categorização dos simulacros sofre ainda mais rebaixamento, pois eles localizam-se de mais a mais afastados do artefato original, circundante longínquo no mundo das ideias.

Revendo essa linha de raciocínio, Deleuze discute, séculos depois, no texto Platão e o Simulacro, a relação pensada pelo filósofo grego entre as cópias e os simulacros. O filósofo francês, por sua vez, explica que, as primeiras "são possuidoras em segundo lugar, pretendentes bem fundados, garantidos pela 
semelhança"13. Já os simulacros, supostamente em categorização inferior, são marcados a princípio “como os falsos pretendentes, constituídos a partir de uma dissimilitude, implicando uma perversão, um desvio essencial" ${ }^{14}$.

O falso pretendente, o simulacro, seria o próprio sofista e sobre ele Platão questiona a noção de cópia, de modelo. Dessa forma, quanto à pretensão de legitimidade buscada pelo filósofo grego, Deleuze indica que a motivação platônica seleciona as boas e más cópias. As boas seriam os pretendentes bem fundados, devido ao menor distanciamento em relação ao nível das ideias; já as más cópias, os simulacros, estariam ainda mais afastadas do original e seriam o mais precário de todos os níveis de representação.

Esteticamente, o filósofo francês chama atenção para a dualidade dilacerante dessa implicação. De um lado estaria a teoria da sensibilidade como uma forma de experiência possível e, de outro, a teoria da arte reflexiva como experiência real. Ele assinala que "para que os dois sentidos se juntem é preciso que as próprias condições da experiência em geral se tornem condições de experiência real"15.

Contudo, discutindo a reversão ao platonismo e abalando a noção de representação, Deleuze discorre sobre a potencialidade do simulacro ao longo do texto. Para o autor, “o simulacro não é uma cópia degradada, ele encerra uma potência positiva que nega tanto o original como a cópia, tanto o modelo como a

\footnotetext{
${ }^{13}$ Gilles Deleuze, Op. Cit., 2015, p. 259-272.

${ }^{14}$ Ibidem, p. 262.

${ }^{15}$ Ibidem, p. 265.
} 
reprodução" ${ }^{16}$ porque o objetivo da divisão platônica não seria, em absoluto, a divisão de gêneros, mas a seleção de linhagens.

É nesse contexto, e diante dos escritos carolinianos apresentados na seção acima, que nos parece relevante analisar ao menos duas perspectivas dessa abordagem, embora uma delas, de início, possa causar certo estranhamento. A primeira perspectiva busca refletir sobre a possibilidade dos textos selecionados serem o que Platão considera como cópias bem fundadas, mais próximas da ideia original. E a segunda, compartilhando da defesa de Deleuze quanto ao simulacro, considera esses mesmos textos como potentes simulacros.

A leitura do texto A Empregada e escritos da obra Diário de Bitita, além do conhecimento de dados da sua biografia, boa parte deles apresentados pela própria escritora na vastidão de sua produção, nos remete novamente ao aforismo Conhece-te a ti mesmo. Carolina Maria de Jesus não somente buscou conhecer a si mesma, registrando esse exercício nas folhas de papel, como também lutou para ser conhecida e reconhecida pelo que essencialmente era: uma escritora.

Os relatos destacados em Diário de Bitita, nos apresentam a experiência memorística do seu corpo servil. Seu trabalho como cozinheira na Santa Casa de Misericórdia ou como espécie de caseira na casa da senhora Salimas, lhe rendeu experiências vívidas e dolorosas. Tempos depois, essas mesmas experiências embasam sua escrita literária, como uma plasmagem da realidade.

${ }^{16}$ Ibidem, p. 267. 
A proposta é pensar, então, como o primeiro nível de conhecimento caroliniano, especificamente entendido neste texto não como o nível das ideias, mas como a experiência servil vivida pela escritora na juventude, oportuniza a realização de outros níveis dentro da sua produção, aqueles apontados por Platão como cópia e simulacro e repensados por Deleuze.

Obviamente que não se pretende propor um espelhamento direto com os níveis categorizados por Platão em relação ao mundo das ideias e suas representações. Trata-se muito mais de uma quimera, um devaneio no sentido mais amplo que esse termo possa alcançar. Por isso, em meio a um devaneio filosófico, propõe-se estabelecer, em certa medida, uma aproximação entre categoria do mundo intangível das ideias com as experiências vividas pelo corpo tangível.

Baseadas nessa plasmagem, as experiências vividas por Carolina de Jesus em relação aos trabalhos realizados como servente, poderiam ser classificadas paralelamente como o primeiro nível do conceito platônico. Na experiência estaria o original, o ponto de partida para o forjamento das representações. Evidente que não se pode pensar em uma equidade com o mundo das ideais, mas a experiência, marcada na memória e no corpo, significa, nesse contexto, a imagem primeira para a representação. Já para Deleuze, seria a própria apresentação do corpo em sofrimento.

Assim compreendido, Carolina Maria de Jesus plasma, em seu texto poético-narrativo e autobiográfico, a experiência atravessada pelo seu corpo tangível. Ao descrever literariamente em A Empregada boa parte da cena memorística relatada nos registros de Diário de Bitita, ela produz - construindo 
um paralelo com a categorização platônica - uma cópia mais próxima do original, constituída de semelhança e possibilitada pela ação do processo de autoconhecimento.

Ao aceitar o devaneio filosófico que, em certa medida, tenta aproximar-se da categorização platônica, o texto caroliniano, mais próximo do nível original aqui assumido, novamente, como o nível da experiência vivida no corpo e registrada na memória - é a boa cópia, dotada de semelhança e bem fundada a que se refere o filósofo francês no diálogo com Platão apontado em, "a cópia platônica é o semelhante: o pretendente que recebe em segundo lugar"17.

Despertado do devaneio, e partindo para o terceiro nível de representação, é possível pensar esse mesmo recorte caroliniano de experiência plasmada na escrita como um simulacro dotado de especificidade, dessa forma, potente, como defende Deleuze quando afirma que por suas marcadas características o simulacro "rompe suas cadeias e sobe à superfície: afirma então sua potência de fantasma, sua potência recalcada"18. Diante disso, nos termos do distanciamento da ideia original, o simulacro não teria um quê de fundamento outro, que a cópia não alcança?

O ponto de reversão de Deleuze funda-se justamente na potência do simulacro e não na precariedade de sua dissimilitude, potência que define, segundo ele, a modernidade. Ainda para o filósofo francês, fora Platão quem balizou os domínios da representação, mas o desdobrar desse domínio como bem fundado, limitado e finito coube a Aristóteles. Revendo a grande trindade

\footnotetext{
${ }^{17}$ Ibidem, p. 264.

${ }^{18}$ Ibidem, p. 266.
} 
platônica (usuário, produtor e imitador), Deleuze defende que o observador não pode dominar as dimensões, profundidades e distâncias implicadas pelo simulacro. Diversamente, “o observador faz parte do próprio simulacro, que se transforma e se deforma com seu ponto de vista"19.

Ao discutir a reversão do platonismo, afirmando que, ao invés de deixar na sombra a motivação platônica, "reverter o platonismo deve significar, ao contrário, tornar manifesta à luz do dia esta motivação, ‘encurralar' esta motivação - assim como Platão encurrala o sofista"20, o filósofo francês sugere que se faça emergir os simulacros, que eles proclamem seu direito à diferença, porque para ser parecido é preciso haver diferenças.

Acredita-se que essas diferenças são projetadas devido à especificidade de cada observador e, no contexto desta discussão, também de cada produtor, como Carolina de Jesus, porque o mesmo e o semelhante são ambos simulacros e isso não significa que sejam meramente aparências e ilusões uma vez que "na reversão do platonismo, é a semelhança que se diz da diferença interiorizada, e a identidade do Diferente como potência primeira"21.

Assim, ao compreender que a produção literária de Carolina Maria de Jesus, por meio de uma escritura que plasma suas experiências corpóreas e memorísticas, como observado nos escritos analisados na seção acima, marca as especificidades do seu texto porque sendo a simulação a potência que produz efeito, tal efeito "não é somente no sentido causal, uma vez que a causalidade

\footnotetext{
${ }^{19}$ Ibidem, p. 264.

${ }^{20}$ Ibidem, p. 251.

${ }^{21}$ Ibidem, p. 268.
} 
continuaria completamente hipotética e indeterminada sem a intervenção de outras significações. É no sentido de 'signo', saído de um processo de sinalização"22.

Nesse sentido, o texto caroliniano, que a princípio fora compreendido enquanto boa cópia, uma vez observada a sua proximidade com o nível original, assumido como a experiência vivida e registrada, é agora também concebido como um simulacro potente, já que rompe cadeias e sobe à superfície, afirmando seu direito à diferença. O texto caroliniano é também simulacro porque "é potência para afirmar a divergência e o descentramento. Faz deles o objeto de uma afirmação superior. É sob a potência do falso pretendente que ele faz passar e repassar o que é"23.

Noutra esfera, mas ainda em diálogo com Deleuze, o desejo de dar sentido às coisas faz com que o sujeito busque cada vez mais vontade de potência, essa força vital que move tudo no mundo. Compreender os acontecimentos vividos e expressá-los poeticamente foi a vontade de potência de Carolina Maria de Jesus. Sua produção, mesmo que afastada do nível original, não é uma cópia degradada. Se a simulação designa a potência para produzir um efeito, o efeito produzido pela obra de Carolina de Jesus aproxima a escritora de suas memórias, na busca pelo autoconhecimento e entendimento do mundo.

No entanto, o próprio Deleuze chama atenção para que não se crie confusão entre o factício e o simulacro, afirmando que eles se opõem no coração da modernidade, pois há diferença em destruir para preservar a ordem

\footnotetext{
${ }^{22}$ Ibidem, p. 268.

${ }^{23}$ Ibidem, p. 270.
} 
reestabelecida das representações e destruir para instalar o caos. Para ele, “o factício é sempre uma cópia de cópia, que deve ser levada até o ponto em que muda de natureza e se reverte em simulacro" ${ }^{24}$.

Quanto aos leitores, o texto caroliniano, como todos os demais textos literários, oportuniza o exercício de conhecer ao Outro e a si, compreendendo a realidade forjada via literatura. $\mathrm{O}$ mesmo efeito que aproxima potentemente Carolina Maria de Jesus de si mesma, aproxima seus leitores de si mesmos e também da escritora, num processo circular e contínuo de autoconhecimento. E como apontado longinquamente por divindade grega, o autoconhecimento é necessário para todos: observadores e produtores de sentido.

\section{Algumas considerações finais}

A necessidade de autoconhecimento foi ressaltada pelo mundo grego, que também ocupou-se de tantas outras questões fundamentais para a humanidade. Ao pensar uma sociedade perfeita, Platão se debruçou fortemente na busca pela verdade. Nesse caminho, categorizou os elementos de acordo com a maior ou menor proximidade em relação ao que ele considerava como original, o mundo das ideias. A arte, nesse caso, seria uma simulação mais ou menos precária, de acordo com seu nível de proximidade, do original.

Contudo, simular a realidade é um dos pressupostos da arte, é para cumprir tal tarefa que os variados artistas dedicam seu tempo e intelectualidade. Por meio da representação, historicamente construída, a arte tenta compreender

\footnotetext{
${ }^{24}$ Ibidem, p. 271.
} 
como somos capazes de perceber a nós mesmos, ao Outro e ao mundo. Esse conhecimento produz uma rede de imagens e ideias que, individualmente, decerto, alcança a coletividade.

Primeiramente, foi proposto, nesta abordagem, um devaneio filosófico que concebeu a experiência como ponto de partida em paralelo com a categorização platônica do nível das ideias. Assim, a produção de Carolina Maria de Jesus, foi entendida como uma boa cópia, bem fundada e mais próxima do nível original. Seguidamente, compartilhando com o que Deleuze sugere na reversão do platonismo, conclui-se que a mesma produção de Carolina Maria de Jesus manifesta toda a potência do simulacro por meio da sua unicidade.

Em vista disso, ressignificar a realidade vivida e marcada no corpo por meio das pluralidades de experiências seria, então, elevar o nível imposto ao simulacro. Dentro de leituras de mundo múltiplas e diferenciadas, a potência está justamente na especificidade de representação que o leitor e/ou autor conferem tanto ao que pode ser considerado cópia, como ao simulacro, único porque é uma experiência individualizada na coletividade. Assim, diante de toda a análise realizada, não se pode deixar de dizer, na finalização deste texto, que se considera que a produção de Carolina Maria de Jesus é sim, ao mesmo tempo, a boa cópia e o simulacro potente. 


\section{Referências}

DELEUZE, Gilles. Platão e o Simulacro. In: DELEUZE, Gilles. Lógica do Sentido. São Paulo: Perspectiva, 2015. p. 259-271.

JESUS, Carolina Maria de. Diário de Bitita. São Paulo: SESI-SP, 2014.

JESUS, Carolina Maria de. Meu sonho é escrever... contos inéditos e outros escritos. Organização de Raffaella Fernandez. São Paulo: Ciclo Contínuo, 2018.

PLATÃO. A República. Tradução e Organização de J. Guinsburg. São Paulo: Perspectiva, 2014.

SANTOS, Rosimeire. A Escolarização da população negra entre o final do século XIX e o início do século XX. NetSaber - Artigos. Disponível em: http://artigos.netsaber.com.br/resumo_artigo_6412/artigo_sobre_aescolarizacao-da-populacao-negra-entre-o-final-do-sec--xix-e-o-inicio-do-sec-xx. Acesso em: 16 de março de 2020.

\section{Referência para citação deste artigo}

SILVA, Milena Paixão. Cópia e Simulacro: potencialidades da representação da doméstica em Carolina Maria de Jesus. Revista PHILIA I Filosofia, Literatura \& Arte, Porto Alegre, volume 2, número 1, p. 414 - 437, junho de 2020. 